\title{
Perfil das Merendeiras e Inadequação das Condições Sanitárias e Estruturais de Escolas de uma Cidade do Recôncavo da Bahia - Brasil
}

\section{Profile of the Merendeers and Inadequate of The Sanitary and Structural Conditions of Schools of a City Recôncavo Baiano - Brazil}

Jamille Souza Almeida¹, Ana Lúcia Moreno Amor² e Isabella de Matos Mendes da Silva ${ }^{3}$.

\section{RESUMO}

Cozinhas de creches ou de instituições de ensino assemelham-se mais às domésticas do que às industriais. Avaliou-se a condição estrutural e sanitária (edificações/instalações; equipamentos e utensílios; produção, transporte do alimento e documentação) de 16 escolas e o perfil de 20 manipuladores de alimentos das mesmas. Os resultados obtidos quanto ao perfil dos manipuladores de alimentos revelaram maiores percentuais para: manipuladores do gênero feminino, com média de 50 anos; 1ำ grau incompleto; renda de um salário-mínimo, 11-30 anos de serviço e, demonstrando inadequado conhecimento em relação à manipulação segura. Para as condições sanitárias e estruturais das escolas, a adequação foi baixa: tetos sem acabamento liso, ausência de telas contra insetos, usando utensílios de madeira, sem protetores de cabelo e uniformes, trabalhando com adornos, unhas sujas e conversando no momento da preparação. Registrou-se armazenamento de alimentos com material de higienização, não disponibilização do Manual de Boas Práticas e dos Procedimentos Operacionais Padronizados. Sugere-se, para melhoria dos aspectos sanitários, a implantação das Boas Práticas de Manipulação, criando um ambiente mais seguro, com monitoramento das atividades exercidas pelas merendeiras, bem como adequação físico estrutural dos espaços de produção e distribuição de alimentos, a fim de garantir a oferta segura dos mesmos.

Palavras-chave: Manipuladores de alimentos. Saúde. Higiene.

Kitchens for nurseries or educational institutions look more like domestic ones than industrial ones. The structural and sanitary condition (buildings / facilities, equipment and utensils, production, food transportation and documentation) of 16 schools and the profile of 20 food handlers were evaluated. The results obtained regarding the profile of food handlers revealed higher percentages for: female manipulators, with an average of 50 years; incomplete 1st grade; income of 1 minimum wage, 11-30 years of service and, demonstrating inadequate knowledge regarding safe handling. For the sanitary and structural conditions of the schools, the adequacy was low: unfinished ceilings, no screens against insects, using wooden utensils, no hair guards and uniforms, working with decorations, dirty fingernails and talking at the time of preparation. In order to improve sanitary aspects, it is suggested that the Good Manipulation Practices be implemented, creating a safer environment, with monitoring of the activities carried out by the food vendors, as well as structural physical adequacy of food production and distribution spaces, in order to guarantee the safe offer of them.

${ }^{1}$ Discente do curso de Nutrição da Universidade Federal do Recôncavo da Bahia - CCS/UFRB E-mail: ana_amor@ufrb.edu.br

${ }^{2}$ Nutricionista e Bacharela em Saúde pela Universidade Federal do Recôncavo da Bahia (UFRB).

${ }^{3}$ Bióloga. Docente do Centro de Ciências da Saúde da Universidade Federal do Recôncavo da Bahia - CCS/UFRB

Keywords: Food handlers. Health. Hygiene. 


\section{INTRODUÇÁO}

As normas que regem as chamadas Boas Práticas de Manipulação envolvem requisitos fundamentais que compreendem desde as instalações do estabelecimento, a rígida higiene pessoal, local e dos equipamentos e utensílios e a descrição detalhada dos procedimentos tomados em uma Unidade de Alimentação e Nutrição (NASCIMENTO e BARBOSA, 2007).

A Resolução. RDC 216, de 15 de setembro de 2004, elaborada pela Agência Nacional de Vigilância em Saúde (ANVISA), dispõe dos princípios das Boas Práticas que contemplam o Regulamento Técnico de Boas Práticas para Serviços de Alimentação, estabelecendo os procedimentos corretos com a finalidade de garantir as condições higiênico-sanitárias dos alimentos preparados (BRASIL, 2004), requerendo monitoramento contínuo de todos os processos pelos quais os alimentos passam, assim como das pessoas relacionadas a eles (NASCIMENTO e BARBOSA, 2007).

De acordo com a Organização Mundial de Saúde (WHO, 2010), mais de 60\% dos casos de doenças de origem alimentar decorrem do descuido higiênico-sanitário de manipuladores, das técnicas inadequadas de processamento e da deficiência de higiene da estrutura física, utensílios e equipamentos. O entendimento sobre a percepção de risco, por parte dos manipuladores de alimentos, é primordial para o êxito do programa de treinamento e capacitação em inocuidade de alimentos e para a elaboração de normas em higiene alimentar (KNOX, 2000).

A preocupação com a qualidade nos serviços de alimentação coletiva, como a alimentação escolar, é relevante. Na escola, a alimentação é uma atividade secundária à sua atividade principal, que é a educação (VILA et al., 2014). Considerando que a alimentação escolar objetiva suprir, parcialmente, as necessidades nutricionais dos alunos durante sua permanência na escola e, com isso, melhorar a capacidade de aprendizagem e formar bons hábitos alimentares, o Programa Nacional de Alimentação Escolar (PNAE) garante, por meio da transferência de recursos financeiros, a alimentação escolar dos alunos de toda a educação básica matriculados em escolas públicas e filantrópicas (BRASIL, 2005). Logo a adoção da alimentação saudável nas escolas e a implantação de procedimentos de boas práticas de manipulação de alimentos nos locais de produção e fornecimento de alimentos, tornam-se prioritários (BRASIL, 2006).

A legislação não prevê normas específicas de funcionamento para cozinhas de creches ou qualquer outra instituição de ensino. As normas utilizadas no controle de 
funcionamento de cozinhas em creches são as mesmas que determinam o funcionamento e estrutura de cozinhas industriais (ALMEIDA, 2011).

No caso das escolas, deve-se ficar atento às condições de higiene das cantinas e praças de alimentação. Um lugar que preze pela limpeza e organização demonstra cuidado com a qualidade dos alimentos e respeito pelos consumidores. Ao visitar a cantina da escola, é preciso observar as condições de higiene do espaço destinado à manipulação dos alimentos; como é o abastecimento de água potável para lavagem das mãos e utensílios; se existem condições apropriadas de conservação dos alimentos; além do estado de saúde dos profissionais responsáveis pela manipulação dos alimentos. Caso seja identificada alguma irregularidade, deve-se acionar a diretoria da escola e pedir que entrem em contato com a vigilância sanitária local, para tomar as providências cabíveis (BRASIL, 2008).

Considerando o exposto, o objetivo do estudo foi caracterizar os aspectos socioculturais dos manipuladores, a percepção que os mesmos têm a cerca de higiene e as condições sanitárias em escolas municipais de uma cidade do Recôncavo da Bahia.

\section{MATERIAIS E METODOS}

\subsection{DESENHO DO ESTUDO}

Os dados foram obtidos de escolas municipais de Santo Antônio de Jesus-Bahia, atendidas pelo Programa Nacional de Alimentação Escolar (PNAE), no período de janeiro à maio de 2011, com autorização prévia da Secretaria Municipal de Educação. Atualmente o município possui 45 escolas públicas municipais, sendo distribuídas entre as zonas urbana e rural. A área urbana da cidade conta com 22 escolas localizadas entre o centro e a periferia da cidade. Para esta pesquisa, foi feita uma amostra por conveniência composta por dezesseis escolas da zona urbana, o correspondente a $35,6 \%$ do total de escolas municipais e a $72,7 \%$ das escolas municipais da área urbana, localizadas na periferia e nas proximidades do centro da cidade.

\subsection{INSTRUMENTO DE PESQUISA}

\subsubsection{Para a escola}

Utilizou-se uma análise descritiva, a partir da aplicação, nas escolas, de um formulário (tipo chek list) constante na Resolução de Diretoria Colegiada - RDC - da ANVISA, № . 275/2002 que dispõe de uma Lista de Verificação das Boas Práticas de Fabricação em Estabelecimentos Produtores / Industrializadores de Alimentos (BRASIL, 2002). 
O formulário foi dividido em cinco blocos (1 - Edificações e Instalações; 2 Equipamentos, móveis e utensílios; 3 - Manipuladores; 4 - Produção e Transporte do Alimento e 5 - Documentação), totalizando 164 itens. Para cada item houve a possibilidade de três respostas: "sim" quando o item especificado era atendido; "não", quando não atendia ao item; ou "não aplicável", quando a escola não apresentava a condição especificada.

O bloco 1 foi composto por itens que incluíam as condições da área externa; área interna; piso; teto; paredes; portas, janelas e outras aberturas; iluminação, ventilação e climatização; abastecimento de água; higienização das instalações; e instalações sanitárias, controle de animais e pragas. No bloco 2, equipamentos, móveis e utensílios. $\mathrm{O}$ bloco 3 foi relacionado quanto a vestuário, hábitos higiênicos e programa de capacitação / formação dos manipuladores. No bloco 4 , itens que diziam respeito à recepção e armazenamento dos gêneros alimentícios. E no bloco 5, itens que avaliavam a disponibilidade do Manual de Boas Práticas de Fabricação e dos Procedimentos Operacionais Padronizados nos locais pesquisados.

Com base nos resultados referentes ao percentual de adequação de atendimento aos itens contidos na lista de verificação, as escolas foram classificadas em: grupo 1 (quando atendia de 76 a 100\% dos itens); grupo 2 (quando atendia de 51 a $75 \%$ ); grupo 3 (quando atendia de 0 a $50 \%)$.

\subsubsection{Para as merendeiras}

Para a caracterização do perfil dos manipuladores de alimentos (que preparam a merenda escolar / merendeiras), foram aplicados questionários a 20 manipuladores de alimentos. Para esta etapa, a amostragem do estudo foi composta com a escolha aleatória de 08 escolas, para facilitar o acesso ao grupo a ser pesquisado. 0 questionário aplicado aos manipuladores, teve o intuito de pesquisar variáveis como: caracterização socioeconômica, cultural e do ambiente em que vivem, da atividade realizada (experiência profissional, jornada de trabalho semanal), boas práticas de manipulação e da percepção sobre higiene pessoal e alimentar. Os indivíduos que participaram da amostra foram entrevistados em seus horários de trabalho, sob anuência da direção do estabelecimento de ensino em que trabalhavam.

\subsection{ASPECTOS ÉTICOS}

Previamente esta pesquisa foi submetida e aprovada por Comitê de Ética para pesquisa com Seres Humanos da Faculdade de Tecnologia e Ciências (FTC / Salvador), 
sob o Protocolo $n^{\circ} 3312 / 2011$. Durante a coleta e análise dos dados, os formulários do check list aplicados nos estabelecimentos, receberam códigos com letras e números visando resguardar a identidade da escola. A participação dos envolvidos, esclarecida sobre a finalidade do estudo, expresso por meio do Consentimento Informado Livre Esclarecido. A identificação dos participantes foi mantida em sigilo, assegurando o anonimato e a confidencialidade das informações, não constando nomes dos mesmos nas bases de dados.

\subsection{BANCO DE DADOS E ANÁLISE ESTATÍSTICA}

Os dados quantitativos do questionário foram inseridos e analisados no programa estatístico EPI Info 6 a partir do banco de dados construido no Excel 2007. Além de análise qualitativa a respeito dos conceitos sobre higiene alimentar e pessoal.

\section{RESULTADOS E DISCUSSÄO}

\subsection{PERFIL DAS MERENDEIRAS E PERCEPÇÃO SOBRE HIGIENE ALIMENTAR}

Conhecer o perfil socioeconômico e profissional, bem como o nível de conhecimento dos manipuladores de alimentos, é relevante para o planejamento de políticas públicas e programas de capacitação visando a segurança e qualidade dos alimentos (DEVIDES; MAFFEI; CATANOZI, 2014), a partir do desconhecimento apresentado por estes sobre temática relacionada com insegurança alimentar.

Todos os manipuladores foram do sexo feminino (100\%), com média de idade de 50 anos, variando entre 29 e 65 anos. Com relação à escolaridade, verificou-se que $45 \%$ dos manipuladores possuíam o ensino fundamental incompleto e 30\% com ensino médio completo. Para a renda mensal familiar, $55 \%$ dos entrevistados relataram ganhar um salário mínimo. Neste estudo também foi investigada a presença de animais domésticos nas residências dos entrevistados: 40\% possuíam animais domésticos. Diversos tipos de animais foram relatados, dentre eles: cão (15\%) e gato (10\%) (Tabela 1).

A influência que as condições de saneamento básico têm sobre a saúde da população é notória. Dados sobre o aspecto sanitário do local onde reside os manipuladores de alimentos estão dispostos na Tabela 2. 
Tabela 1. Caracterização sócio-econômica-cultural dos manipuladores de alimentos.

\begin{tabular}{|c|c|c|}
\hline Sexo & n & $\%$ \\
\hline Feminino & 20 & 100 \\
\hline Masculino & 0 & 0 \\
\hline Faixa Etária (anos) & $\mathbf{n}$ & $\%$ \\
\hline $26-30$ & 1 & 5 \\
\hline $31-35$ & 1 & 5 \\
\hline $36-40$ & 1 & 5 \\
\hline $41-45$ & 2 & 10 \\
\hline $46-50$ & 3 & 15 \\
\hline $51-55$ & 6 & 30 \\
\hline $56-60$ & 4 & 20 \\
\hline $61-65$ & 2 & 10 \\
\hline Renda familiar & n & $\%$ \\
\hline$\leq 01 \mathrm{SM}$ & 11 & 55 \\
\hline $02 \mathrm{SM}$ & 7 & 35 \\
\hline $03 \mathrm{SM}$ & 2 & 10 \\
\hline Escolaridade & n & $\%$ \\
\hline 1e grau incompleto & 9 & 45 \\
\hline 1e grau completo & 3 & 15 \\
\hline 20 grau incompleto & 2 & 10 \\
\hline 2egrau completo & 6 & 30 \\
\hline Presença de animal doméstico & n & $\%$ \\
\hline Não possui & 12 & 60 \\
\hline Cão & 3 & 15 \\
\hline Cágado / ta rtaruga & 2 & 10 \\
\hline Gato & 2 & 10 \\
\hline Pássaro & 1 & 5 \\
\hline
\end{tabular}

Oliveira et al. (2008) observaram que 100\% dos manipuladores, de um estudo, realizado em cozinhas de creches públicas e filantrópicas, apresentaram inadequação no item higiene das mãos (lavagem técnica) e $87,5 \%$ no que diz respeito às práticas sanitárias durante a manipulação do alimento. No estudo de Silva, Germano e Germano (2003), referente à higiene pessoal em escolas da rede estadual de ensino em São Paulo, os pesquisadores encontraram valores semelhantes quando comparados com a presente pesquisa. Os autores observaram que em $25 \%$ das unidades não utilizavam o protetor de cabelo e $62,5 \%$ não usavam aventais limpos na cor clara. Esses resultados levaram os autores a concluir que nas unidades escolares visitadas, os locais de preparo e distribuição dos alimentos, bem como a higiene operacional e pessoal dos manipuladores não se encontravam em boas condições higienicossanitárias. 
No mesmo estudo citado acima, os autores fizeram a avaliação e monitoramento da qualidade de alimentos oferecidos na merenda escolar e detectaram que $26,8 \%$ dos manipuladores apresentavam lesões cutâneas, feridas, infecções respiratórias ou gastrintestinais. Este achado não corroborou com o presente estudo, que encontrou apenas 5\% de manipuladores apresentado tais problemas de saúde.

Foi possível verificar que $85 \%$ da população pesquisada tinham reservatório de água encanada em suas residências e a maioria $(35 \%)$ realizando limpeza adequada destes, de forma semestral (Tabela 2). Dados não mostrados indicam que o grupo que não possuía água encanada para beber ou cozinhar, utilizava água advinda de barragens e/ou de poço.

Cerca de $5 \%$ dos manipuladores não possuíam rede de esgoto na residência e $20 \%$ ainda residindo em ruas sem calçamento. Foi possível identificar que todos os indivíduos participantes, tinham coleta de lixo diariamente na rua onde residiam (Tabela 2).

Ao observar a presença ou não de crianças com idade abaixo de 5 anos nas residências da população pesquisada, percebeu-se que $15 \%(n=3)$ dos envolvidos afirmaram haver crianças residindo juntamente com os mesmos (Tabela 2).

Questões da atividade na alimentação coletiva podem ser vistas na Tabela 3. No que diz respeito à porcentagem relativa ao tempo de atividade na área de alimentação coletiva, os dados revelaram que $55 \%(n=11)$ trabalham na área entre 11 e 30 anos. Para justificar o motivo de trabalhar com alimentação escolar, 55\% dos manipuladores entrevistados, relataram executar essa atividade por afinidade, por gostar de trabalhar com alimentos. Em relação à jornada diária de trabalho, $70 \%$ trabalhando 8 horas por dia (Tabela 3 ).

Uma parcela dos manipuladores entrevistados (15\%) demonstrou pouco conhecimento em relação à qualidade e à manipulação segura de alimentos e quanto aos riscos de veiculação de patógenos via alimentar, apesar de $80 \%$ já ter participado de Curso de Capacitação de Boas Práticas em Manipulação de Alimentos. Sobre a responsabilidade dos manipuladores pela saúde dos escolares que ingerem o alimento produzido na escola: $90 \%$ afirmaram que se sentiam responsáveis e 10\% não (Tabela 3).

Apesar do treinamento ser um instrumento importante para aplicação de Boas Práticas (BP) em Unidades de Alimentação e Nutrição (UANs), a conduta do manipulador é muito importante na segurança do alimento. Avaliando o impacto de um curso de capacitação em Boas Práticas de Fabricação (BPF) realizado na cidade de Araraquara-SP, Brasil, com 192 manipuladores de alimentos, os resultados mostraram que este tipo de proposta repercute de forma positiva no nível de conhecimento destes profissionais (DEVIDES; MAFFEI; CATANOZI, 2014). 
DOI 10.18605/2175-7275/cereus.v10n3p103-119
Almeida, J.S., Amor, A.L.M., Silva, I.M.M.

Perfil das merendeiras e inadequação das condições sanitárias e estruturais de escolas de uma cidade do recôncavo da Bahia Brasil.

Tabela 2. Caracterização do ambiente em que vivem os manipuladores de alimentos $-2010$.

\begin{tabular}{|c|c|c|}
\hline Presença de reservatório com água encanada & $\mathrm{n}$ & $\%$ \\
\hline Sim & 17 & 85,0 \\
\hline Não & 3 & 15,0 \\
\hline $\begin{array}{l}\text { De quanto em quanto tempo faz a limpeza do reservatório } \\
\text { de água da residência }\end{array}$ & $\mathrm{n}$ & $\%$ \\
\hline Semanal & 2 & 10,0 \\
\hline 15 dias & 1 & 5,0 \\
\hline Mensal & 2 & 10,0 \\
\hline Trimestral & 2 & 10,0 \\
\hline Semestral & 8 & 40,0 \\
\hline Anualmente & 1 & 5,0 \\
\hline Não sabe / Não lembra & 3 & 15 \\
\hline Nunca fez & 1 & 5,0 \\
\hline Presença de rede de esgoto na residência & $\mathrm{n}$ & $\%$ \\
\hline Sim & 19 & 95,0 \\
\hline Não & 1 & 5,0 \\
\hline Rua com calçamento no local onde reside & $\mathrm{n}$ & $\%$ \\
\hline Sim & 16 & 80,0 \\
\hline Não & 4 & 20,0 \\
\hline Coleta diária de lixo & $\mathrm{n}$ & $\%$ \\
\hline Sim & 20 & 100 \\
\hline Não & 0 & 0 \\
\hline Presença de crianças abaixo de 05 anos & $\mathrm{n}$ & $\%$ \\
\hline Sim & 3 & 15,0 \\
\hline Não & 17 & 85,0 \\
\hline
\end{tabular}


Nas escolas estudadas no Recôncavo da Bahia observou-se que as condutas de BP nem sempre eram seguidas. Essas práticas incorretas podem levar a contaminação alimentar e favorecer o crescimento e desenvolvimento de patógenos e causar Doenças de Transmissão Alimentar (DTA).

Em relação aos conceitos de higiene alimentar, a idéia mais presente nas falas dos manipuladores foi a necessidade de lavar os alimentos antes da preparação ou consumo. Sobre o conceito de higiene pessoal, a maioria especificou tomar banho todos os dias e cortar as unhas.

Corroborando com os dados de Castro, Barbosa e Tabai (2011) quanto ao perfil dos manipuladores de alimentos de restaurantes self-service nos shoppings da cidade do Rio de Janeiro, independentemente da condição socioeconomica dos manipuladores de alimentos, estes possuem baixo conhecimento sobre alimento seguro e sobre insegurança alimentar.

A percepção é o processo pelo qual o ser humano toma consciência dos fatos e de suas relações num contexto ambiental (fixação). Embora o ambiente influencie significativamente na percepção, aquilo que é percebido depende das habilidades construtivas, da fisiologia e das experiências, ou seja, a percepção depende da capacidade de atentar (ponto de fixação da pessoa), dos interesses e motivações e das experiências passadas (DAVIDOFF, 2001). Segundo Fischer e Guimarães (2002), a percepção de risco influencia no comportamento do indivíduo e no grau de precaução perante situações que possam ocasionar acidentes. Desta forma, a fim de modificar o comportamento e incorporar novas atitudes, neste caso, relacionadas com segurança alimentar, é necessário que o indivíduo tenha a percepção adequada do risco da atividade que exerce.

\subsection{Condições sanitárias e estruturais das escolas municipais}

Quanto ao percentual de adequação das condições higiênico-sanitárias das escolas estudadas, o resultado foi baixo, variando de $27,2 \%$ a $57,8 \%$ (Tabela 4 ).

No bloco 1 (Figura 1), 81,2\% das escolas foram classificadas no grupo 3, observandose tetos sem acabamento liso, ausência de telas contra insetos e de lixeiras com tampa, acesso comum a outros ambientes escolares, manipuladores utilizando as instalações sanitárias de alunos e funcionários, sendo que as mesmas não possuíram, na sua maioria, sabonetes para higienização das mãos; luminárias sem proteção contra quebras e em algumas escolas as instalações elétricas exteriores não estavam revestidas; a ventilação 
natural não garantia o conforto térmico e, em alguns casos, fazendo-se uso de ventiladores; os reservatórios de água não possuem registro de frequência de higienização.

Tabela 3 - Dados do trabalho com alimentação - Manipuladores de alimentos - 2010.

\begin{tabular}{|l|l|l|}
\hline Tempo de atividade & $\mathbf{n}$ & $\%$ \\
\hline 11 a 30 anos & 11 & 55,0 \\
\hline 6 a 10 anos & 3 & 15,0 \\
\hline 2 a 5 anos & 4 & 20,0 \\
\hline Não sabe & 2 & 10,0 \\
\hline Motivos para o trabalho com alimentos & $\mathbf{n}$ & $\%$ \\
\hline Por afinidade / gostar de trabalhar com alimentos & 11 & 55,0 \\
\hline Por aprovação em processo seletivo (concurso) & 4 & 20,0 \\
\hline Remanejamento de outras áreas para alimentação escolar & 3 & 15,0 \\
\hline Não sabe & 2 & 10,0 \\
\hline Jornada diária de trabalho & $\mathbf{n}$ & $\%$ \\
\hline 06 horas & 6 & 30,0 \\
\hline 08 horas & 14 & 70,0 \\
\hline Participação em Curso de Capacitação de Boas Práticas & $\mathbf{n}$ & $\%$ \\
\hline Sim & 16 & 80,0 \\
\hline Não & 4 & 20,0 \\
\hline Alimentos podem veicular patógenos & $\mathbf{n}$ & $\%$ \\
\hline Sim & 3 & 15,0 \\
\hline Não & 17 & 85,0 \\
\hline Sente-se responsável pela saúde do escolar & $\mathbf{n}$ & $\%$ \\
\hline Sim & 18 & 90,0 \\
\hline Não & 2 & 10,0 \\
\hline & & \\
\hline
\end{tabular}


No bloco 2 (Figura 1), 62,5\% das escolas foram classificadas no grupo 3, registrandose a utilização de utensílios de madeira e de utensílios guardados em baldes.

O bloco 3 (Figura 1) teve $68,75 \%$ das escolas como integrantes do grupo 2; observando-se que $45 \%$ dos manipuladores não usavam protetores de cabelo, 100\% não utilizavam uniformes adequados, $80 \%$ apresentavam adornos, $65 \%$ apresentavam unhas sujas ou com esmalte, $90 \%$ conversavam no momento da preparação e $95 \%$ não usavam sapatos fechados.

A análise do bloco 4 (Figura 1) permitiu classificar 93,3\% das escolas no grupo 3, com registro de armazenamento de alimentos juntamente com material de higienização e a rede de frio não é adequada ao volume e aos diferentes tipos de matérias-primas e ingredientes utilizados no preparo da merenda escolar.

Em relação ao bloco 5 (Figura 1), mesmo com a RDC №. 216/2004 em vigor, foi encontrado, neste bloco, níveis de atendimentos muito baixos. Foi verificado que $100 \%$ das escolas tiveram classificação no grupo 3 , não atendendo a nenhum item; como por exemplo, disponibilização do Manual de Boas Práticas e dos Procedimentos Operacionais Padronizados, documentos preconizados pelas Resoluções RDC 275/2002 (BRASIL, 2002) e RDC 216/2004 (BRASIL, 2004), respectivamente.

De acordo com o check-list do estudo, é possível perceber que um percentual baixo de adequação das condições higienico-sanitárias, uma vez que segundo a resolução RDC 275/2002 (BRASIL, 2002), Art. $3^{\circ}$ parágrafo 1丷, os estabelecimentos devem atender a todos os itens discriminados na Lista de Verificação das Boas Práticas de Fabricação em Estabelecimentos Produtores / Industrializadores de Alimentos.

Dados com percentual de inadequação do ambiente alimentar relativamente menor ao visualizado neste estudo foram encontrados em outros trabalhos. Rodrigues (2007) em seu estudo observou que todas as escolas se enquadravam no grupo 3 por atender menos de $51 \%$ dos itens avaliados. Os resultados de adequação obtidos estavam entre $18 \%$ e 37\%. Em outro, realizado em 10 escolas públicas municipais de Sobral (CE) por Façanha et al. (2002), permitiu classificar as escolas como "regular" no que diz respeito ao aspecto de higiene do ambiente, dos equipamentos e utensílios, pessoal e dos alimentos. Ravagnani e Sturion (2009) que encontraram um percentual médio de $37,5 \%$ de não conformidade em dois Centros Educacionais, também se depararam com valores semelhantes aos estudos de outros autores. 
Tabela 4. Percentual de adequação de áreas de preparo da alimentação escolar.

\begin{tabular}{|l|c|l|}
\hline Escolas & Conforme (\%) & Não conforme (\%) \\
\hline E1 & 34,35 & 65,60 \\
\hline E2 & 44,03 & 55,97 \\
\hline E3 & 40,29 & 59,71 \\
\hline E4 & 47,73 & 52,27 \\
\hline E5 & 33,33 & 66,67 \\
\hline E6 & 27,20 & 72,80 \\
\hline E7 & 29,29 & 70,71 \\
\hline E8 & 43,28 & 56,72 \\
\hline E9 & 36,36 & 63,63 \\
\hline E10 & 42,31 & 57,69 \\
\hline E11 & 31,62 & 68,38 \\
\hline E12 & 35,21 & 64,79 \\
\hline E13 & 57,85 & 42,15 \\
\hline E14 & 36,92 & 63,08 \\
\hline E15 & 36,43 & 63,08 \\
\hline E16 & 34,56 & 65,44 \\
\hline
\end{tabular}


Isto permite afirmar que o presente estudo encontrou valores que também descumprem a RDC № 216 (BRASIL, 2004) e o que recomenda o PNAE.

Uma pesquisa feita por Silva, Germano e Germano (2003) verificou que as condições de limpeza e conservação de equipamentos e utensílios da rede estadual de ensino de São Paulo estavam em boas condições em apenas $37,5 \%$ das unidades; apresentando os seguintes itens com maiores irregularidades: a limpeza de fogões, de geladeiras, de pisos e de paredes.

Segundo Hazelwood e McLean (1994) não é recomendável utilizar utensílios de madeira no preparo de alimentos, uma vez que este material é muito absorvente, promovendo o acúmulo de microrganismos, que podem rapidamente causar intoxicação e contaminação cruzada dos produtos alimentícios.

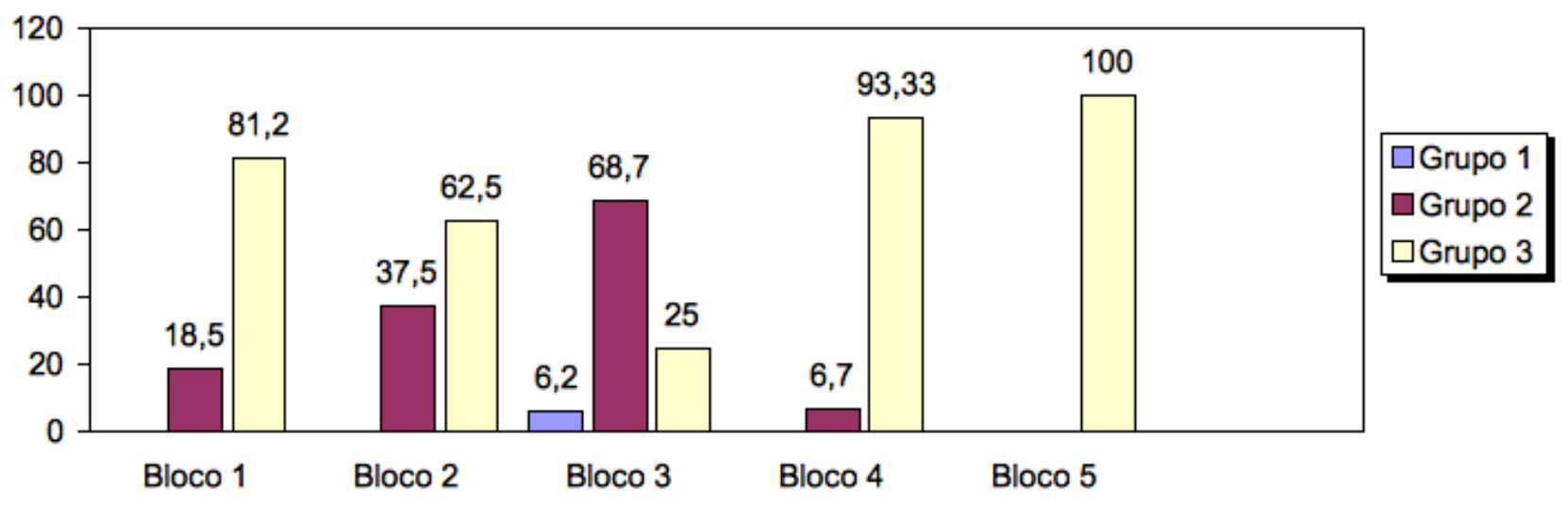

Figura 1. Porcentagem de adequação por categoria em áreas de preparo da alimentação escolar.

Farche et al. (2007), relataram nas cozinhas das escolas da rede pública de FrancaSP, o uso de utensílios de madeira e o armazenamento inadequado de utensílios guardados em caldeirões, sem proteção. Resultados bem semelhantes aos encontrados nas escolas de Santo Antônio de Jesus (Bahia). Chesca et al. (2003), em seu estudo, encontraram $100 \%$ dos equipamentos e utensílios oferecendo riscos de contaminação aos alimentos em uma UAN (Unidade de Alimentação e Nutrição) na cidade de Uberaba, MG.

Silva e Souza (2007), avaliando a condição higiênico-sanitária do preparo da merenda escolar, no colégio de aplicação da Universidade Federal do Acre, em Rio Branco, expuseram que o armazenamento das matérias-primas não perecíveis estava em contato direto com as paredes, em prateleiras expostas. No tocante, o estudo de Torres (2007), em cantina escolar de Viçosa (MG), verificaram maior inadequação no que diz respeito ao 
armazenamento de alimentos, principalmente no armazenamento frio. Farche et al. (2007) observaram a ausência de termômetro para monitorar a temperatura dos freezers e geladeiras.

Decorrente do exposto acima e enfatizado por Colombo, Oliveira e Silva (2009), a fiscalização nos ambientes de alimentação coletiva (como as escolas) deve ser periódica para se detectar possíveis irregularidades.

Na profilaxia e controle de agentes infecciosos e parasitários que são veiculados por água e alimentos, a melhoria do nível sócio-econômico-cultural e sanitário da população é de fundamental importância. As medidas preventivas devem ser aplicadas levando-se em consideração cada tipo de agente e sua relação com o meio ambiente (PEDRAZZANI et al., 1990).

Visto que, como supracitado, a legislação brasileira não prevê normas específicas de funcionamento para cozinhas de creches ou qualquer outra instituição de ensino, estudos que avaliem as condições sanitárias em escolas (municipais, públicas ou estaduais), como este, mostram-se originais. Principalmente quando somados com a caracterização do manipulador envolvido na produção da merenda, seu perfil e percepções a cerca de higiene dos alimentos preparados, tornando-se relevantes para controle e combate à insegurança alimentar, mostrando pioneirismo com este tipo de temática. Evidenciando o ponto forte da proposta, ratificando a necessidade de uma maior formação dos envolvidos no processo de preparo dos alimentos e a avaliação constante das condições estruturais dos espaços que trabalham com alimentos.

\section{CONSIDERAÇOES FINAIS}

Considerando que o Programa Nacional de Alimentação Escolar (PNAE) visa oferta de uma alimentação saudável, adequada e segura aos escolares; as escolas avaliadas alcançaram um nível baixo de qualificação conforme a classificação proposta pela legislação, demonstrando precariedade no controle higiênico-sanitário.

Os resultados demonstram que nas escolas analisadas, existem lacunas sob a ótica da segurança e da qualidade quanto aos itens necessários para a produção de alimentos. Em todos os blocos avaliados foram identificadas inconformidades, com maior destaque para os manipuladores de alimentos, documentação e registro. 
O perfiil das merendeiras quanto a concepções e conceitos sobre a temática alimentar voltada para aspectos relacionados com insegurança alimentar, verificou-se que estas demonstraram dificuldades quanto à compreensão do prórpio universo de trabalho e sobre os cuidados sanitário dos alimentos, interferindo com isso na prevenção de agentes infecciosos e/ou parasitários transmitidos por via hídrica ou alimentar e na consequente promoção à saúde no ambiente escolar.

Sugere-se, para melhoria dos aspectos sanitários, a implantação das Boas Práticas de Manipulação, criando um ambiente mais seguro, com monitoramento das atividades exercidas pelas merendeiras, bem como adequação físico estrutural dos espaços de produção e distribuição de alimentos, a fim de garantir a oferta segura dos mesmos. Medidas que teriam por objetivo principal a máxima redução de riscos, a fim de proporcionar alimentos inócuos e criar um ambiente de trabalho mais eficiente e satisfatório.

\section{AGRADECIMENTOS}

A todas merendeiras participantes deste estudo.

\section{REFERENCIAS}

ALMEIDA, J. S. Qualidade microbiológica da merenda escolar e investigação de agentes infecciosos e parasitários em manipuladores de alimentos de escolas da rede municipal de ensino. [Trabalho de Conclusão de Curso]. Centro de Ciências da Saúde / Universidade Federal do Recôncavo da Bahia, 2011.

BRASIL. Agência Nacional de Vigilância em Saúde - ANVISA, Resolução - RDC 216, de 15 de setembro de 2004. Disponível em: <http://www.anvisa.gov.br>. Acesso em: $10 \mathrm{de}$ jun. 2011.

BRASIL. Agência Nacional de Vigilância Sanitária. Vigilância Sanitária e Escola: parceiros na construção da cidadania/ Agência Nacional de Vigilância Sanitária. - Brasília: Anvisa, 2008. 120 p. ISBN 978-85-88233-34-8.

BRASIL. Casa Civil. Lei n. 11.346, de 15 de setembro de 2006. Cria o Sistema Nacional de Segurança Alimentar - SiSAN com vistas em assegurar o direito humano à alimentação adequada e dá outras providências. Brasília; 2006.

BRASIL. Ministério da Saúde. Agência Nacional de Vigilância Sanitária. Resolução RDC no 275, de 21 de outubro de 2002. Dispõe sobre o Regulamento Técnico de Procedimentos Operacionais Padronizados aplicados aos Estabelecimentos Produtores / Industrializadores de Alimentos e a Lista de Verificação das Boas Práticas de Fabricação em Estabelecimentos Produtores/Industrializadores de Alimentos. Disponível em: < 
http://www.anvisa.gov.br/anvisalegis/resol/2002/275_02rdc.htm> Acessado em maio 2011.

BRASIL. Ministério da Educação. Programa Nacional de Alimentação Escolar. Brasília: MEC; 2005. Acessado 2013 fev. Disponível em http://www.portaltransparencia.gov.br/aprendaMais/documentos/curso_PNAE.pdf.

CASTRO, F.T.; BARBOSA, C. G.; TABAI, K. C. Perfil de manipuladores de alimentos e a ótica desses profissionais sobre alimento seguro no Rio de Janeiro (RJ). Oikos: Revista Brasileira de Economia Doméstica, Viçosa, v. 22, n.1, p.153-170, 2011.

CHESCA, A. C.; MOREIRA, P. A.; ANDRADE, S. C. B. J.; MARTINELLI, T. M. Equipamentos e utensílios de unidades de alimentação e nutrição: um risco constante de contaminação das refeições. Hig. Aliment., v17, n.114/115, p.20-3, 2003.

COLOMBO, M.; OLIVEIRA, K .M. P.; SILVA, D. L. D. Conhecimento das merendeiras de Santa Fé, PR, sobre higiene e boas práticas de fabricação na produção de alimentos.

Revista Higiene Alimentar, vol. 23, no 170/171, março/abril - 2009.

DAVIDOFF, L. L. Introdução à Psicologia. São Paulo: Pearson Education do Brasil, 2001. p. 141-145.

DEVIDES, G. G. G.; MAFFEI, D. F.; CATANOZI, M. P. L. M. Perfil socioeconômico e profissional de manipuladores de alimentos e o impacto positivo de um curso de capacitação em Boas Práticas de Fabricação. Braz. J. Food Technol., Campinas, v. 17, n. 2, p. 166-176, abr./jun. 2014. DOI: http://dx.doi.org/10.1590/bjft.2014.014

FAÇANHA, S. H. F; FERREIRA, N. D. L.; MONTE, A. L. S.; PONTES, A. R. Avaliação da garantia da qualidade higiênico-sanitária do programa de alimentação escolar da cidade de Sobral - CE. Revista Higiene Alimentar, v 16 n.100, p 54-58, set, 2002.

FARCHE, L. M.; PEREIRA, C. H. C.; CASTRO, G. P. P., PELIZER, L. H. O panorama higiênico-sanitário nas cozinhas das escolas da rede pública de Franca, SP. Revista Higiene Alimentar, v. 21, n. 154, p. 27 - 29, set. 2007.

FISCHER, D.; GUIMARÃES, L. B. M. Percepção de risco e perigo: um estudo qualitativo. In: Congresso Brasileiro de Ergonomia da Abergo 12., 2002, Recife. Anais...

Pernambuco: ABERGO, 2002. Disponível em:

<www.producao.ufrgs.br/arquivos/arquivos/045.pdf>. Acesso em: 09 jun. 2011.

KNOX, B. Consumer perception and understanding of risk from food. Br. Med. Bull, v. 56, n. 1, p. 97-109, 2000.

HAZELWOOD, E. D.; McLEAN, A. C. Manual de higiene para manipuladores de alimentos. São Paulo: Livraria Varela, 1994.

NASCIMENTO, G. A.; BARBOSA, J. S. BPF - Boas Práticas de Fabricação: uma revisão. São Paulo. Revista Higiene Alimentar, v. 21, n. 148, p. 24-30, 2007.

OLIVEIRA, M. N.; BRASIL, A. L. D.; TADDEI, J. A. A. C. Avaliação das condições higiênico-sanitárias das cozinhas de creches públicas e filantrópicas. Ciência e Saúde Coletiva, Rio de Janeiro, v.13, n.3, p. 1051-1060, mai./jun. 2008. 
PEDRAZZANI, E. S.; MELLO, D. A.; PIZZIGAT, C. P.; BARBOSA, C. A. A. Aspectos educacionais da intervenção em helmintos intestinais no subdistrito de Santa Eudóxia, município de São Carlos - SP. Caderno de Saúde Públ., 6: 74 - 85, 1990.

RAVAGNANI, E. M.; STURION, G. L. S. Avaliação da viabilidade de implementação das boas práticas em unidades de alimentação e nutrição de centros de educação infantil de Piracicaba, São Paulo. Rev. SAN, v. 16, n. 2, p. 43-59, 2009.

RODRIGUES, G. K. D. Segurança Alimentar em Unidades de Alimentação e Nutrição escolar: aspectos higiênico-sanitários e produção de resíduos orgânicos. Viçosa Minas Gerais, 2007. Disponível em: <htpp: www.scielo.com.br>. Acesso em: 01 de jan. de 2011.

SILVA, C.; GERMANO, M. I. S.; GERMANO, P. M. L. Conhecimento dos manipuladores da merenda escolar em escolas da rede estadual de ensino em São Paulo, SP. Revista de Higiene Alimentar, São Paulo, v. 17, n. 113, p. 46-51. out. 2003.

SILVA, L.; SOUZA, M. L. Avaliação higiênico-sanitária do preparo da merenda escolar, no colégio de aplicação da Universidade Federal do Acre, em Rio Branco. Revista Higiene Alimentar, v. 21, n. 155, p. 16 - 22, out. 2007.

TORRES, S. A. M. Análise das condições higiênico-sanitárias durante o preparo da alimentação em cantina escolar. Revista Higiene Alimentar, v. 21, n. 153, p. 14 - 18, jul./agost. 2007.

VILA, C.V.D.; SILVEIRA, J.T.; ALMEIDA, L.C. Condições higiênico-sanitárias de cozinhas de escolas públicas de Taqui, Rio Grande do Sul, Brasil. Vig Sanit Debate, v. 2, n. 2, p. 67-74, 2014.

WHO. World Health. Organization. Foodborne disease. Disponível em: <http://www.who.int/topics/foodborne_diseases/en/>. Acesso em: 3 jun. 2010. 